\title{
Avaliação microbiológica da água de consumo de casas localizadas em área alagada em um município do estado Amapá
}

\author{
Microbiological evaluation of drinking water of houses located in a flooded area in the \\ municipality of Amapá
}
Evaluación microbiológica del agua potable en casas ubicadas en una zona inundada en un municipio del estado de Amapá

Claude Porcy ${ }^{1}$, Taynara da Silva Costa ${ }^{1}$, Vanessa Helena Pires da Costa do Nascimento ${ }^{1}$, Valentim Silva Monteiro ${ }^{1}$, Joziele Neves Nogueira ${ }^{1}$, Rubens Alex de Oliveira Menezes ${ }^{2 \star}$.

\section{RESUMO}

Objetivo: Realizar análise microbiológica da água de consumo distribuídos via tubulação hidráulica para as residências localizadas em um bairro alagado em um município do Amapá. Métodos: Estudo transversal, descritivo, quantitativo, realizado através de coletas de amostras de água de 23 residências em duplicata identificadas como (A e B), totalizando 46 amostras analisadas no ano de 2019. Para a análise das coletas foi utilizado o método de Número Mais Provável, que estabelece a quantidade de coliformes por $100 \mathrm{~mL}$, fornecendo informações a respeito da potabilidade da água. Resultados: A análise microbiológica das amostras coletadas das 23 residências revelou que 8 casas $(34,8 \%)$ tiveram resultados positivos para coliformes totais e 6 casas (26.1\%), positivos para coliformes termotolerantes. Em relação as bactérias heterotróficas, 13 casas $(56,5)$ apresentaram resultados positivos, sendo que 11 dessas casas $(84,6 \%)$ apresentaram resultados superiores a $500 \mathrm{UFC} / \mathrm{mL}$. Foi observado a contaminação da água por coliformes fecais de algumas residências, em decorrência das encanações submersas e das precárias condições das instalações hidráulicas. Conclusão: Embora as casas sejam servidas por água da rede de abastecimento de tratamento da cidade, a falta de manutenção nas encanações e o contato com a água da área alagada, pode ser um dos fatores contribuidores para essas contaminações.

Palavras-chave: Análise da água, Colimetria, Análise microbiológica, Ingestão de líquidos, Padrão de potabilidade da água.

\begin{abstract}
Objective: Conduct microbiological analysis of drinking water distributed via hydraulic pipes to homes located in a flooded neighborhood in a municipality in Amapá. Methods: Cross-sectional, descriptive and quantitative study, carried out by collecting water samples from 23 duplicate households identified as (A and B), totaling 46 samples analyzed in the year 2019. For the analysis of the collections, the Most Probable Number method was used, which establishes the quantity of coliforms per $100 \mathrm{~mL}$, providing information about the water potability. Results: Microbiological analysis of samples collected from 23 residences revealed that 8 houses (34.8\%) were positive for total coliforms and 6 houses $(26.1 \%)$ positive for thermotolerant coliforms. Regarding heterotrophic bacteria, 13 houses (56.5) presented positive results, and 11 of these houses (84.6\%) presented results above $500 \mathrm{CFU} / \mathrm{mL}$. Water contamination was observed by faecalis coliforms in some households, due to submerged pipes and poor conditions of the hydraulic installations. Conclusion: Although houses are served by water from the city's treatment supply network, lack of maintenance in the pipelines and contact with water from the flooded area may be a contributing factor to these contaminations.
\end{abstract}

Keywords: Water analysis, Colimetry, Microbiological analysis, Fluid intake, Water potability standard.

\footnotetext{
${ }^{1}$ Faculdade Estácio de Macapá, Macapá-AP.

2 Universidade Federal do Amapá, Macapá-AP. *E-mail: rubens.alex@unifap.br
} 


\section{RESUMEN}

Objetivo: Realizar análisis microbiológicos del agua potable distribuida a través de tuberías hidráulicas a hogares ubicados en un barrio inundado en un municipio de Amapá. Métodos: Se realizó un estudio transversal, descriptivo y cuantitativo mediante la recolección de muestras de agua de 23 hogares duplicados identificados como ( $\mathrm{A}$ y B), totalizando 46 muestras analizadas en el año 2019. Para el análisis de las colecciones, se utilizó el método de Número más probable, que establece la cantidad de coliformes por 100 $\mathrm{ml}$, proporcionando información sobre la potabilidad del agua. Resultados: El análisis microbiológico de las muestras recolectadas de 23 residencias reveló que 8 casas $(34.8 \%)$ fueron positivas para coliformes totales y 6 casas $(26.1 \%)$ positivas para coliformes termotolerantes. Con respecto a las bacterias heterotróficas, 13 casas (56.5) presentaron resultados positivos, y 11 de estas casas (84.6\%) presentaron resultados superiores a 500 UFC/ mL. La contaminación del agua se observó por coliformes fecales en algunos hogares, debido a las tuberías sumergidas y las malas condiciones de las instalaciones hidráulicas. Conclusión: Aunque las casas reciben agua de la red de suministro de tratamiento de la ciudad, la falta de mantenimiento en las tuberías y el contacto con el agua del área inundada puede ser un factor que contribuya a estas contaminaciones.

Palabras clave: Análisis de agua, Colimetría, Análisis microbiológico, Ingesta de fluidos, Estándar de potabilidad de agua.

\section{INTRODUÇÃO}

A água é essencial para a manutenção da vida no planeta. No entanto, apenas $0,3 \%$ se encontra em lugares de fácil acesso (rios, lagos e atmosfera). O restante encontra-se in natura, imprópria para o consumo ou em lugares de difícil acesso, o que se torna inviável sua utilização ou deixa mais cara sua extração, ou seja, $97,5 \%$ de água encontra-se sob a forma de água salgada e 2,5\% encontra-se em aquíferos ou em geleiras. Por conta disso, são necessárias a conservação e a preservação da água, tendo em vista ser um recurso reduzido (BARROS FGN e AMIN MM, 2008).

Ao longo da história, diversas modificações ocorreram na relação do homem com a natureza e, por conseguinte, a água deixou de ser vista como um bem natural e passou a ser vista materialmente como um recurso hídrico.

Adicionalmente, seu uso passou a ser indiscriminado e sem avaliar as consequências ambientais em relação à quantidade e qualidade, gerando uma série de alterações no ciclo hidrológico e na sua qualidade para consume, e isso se deve pela complexidade da organização das sociedades humanas (NOGUEIRA EFR, et al., 2018).

Para Nogueira EFR, et al (2018), a água pode se tornar um veículo capaz de transmitir uma série de agentes patogênicos e substâncias nocivas, influenciando diretamente na saúde da população carente e de baixa renda.

Esses fatores justificam a importância do controle da qualidade da água como necessidade universal e exige atenção tanto por parte das autoridades sanitárias como dos consumidores, sobretudo no que diz respeito à água destinada ao consumo humano.

A qualidade da água fornecida é um dos critérios para verificar a saúde da população. Nesse contexto, os principais contaminantes presentes na água são os coliformes totais e termotolerantes, indicadores do contato direto ou indireto com material fecal, levando a infeções hídricas e/ou intoxicações alimentares, causadas por fungos, bactérias, vírus, parasitas patogênicos e toxinas microbianas. As bactérias são responsáveis por aproximadamente $90 \%$ dos casos, e as mais encontradas são Escherichia coli, Salmonella spp., Staphylococcus aureus e Yersinia enterocolitica (SALES WB, et al. 2015).

Adicionalmente, as doenças diarreicas e de veiculação hídrica incluem uma diversidade de agentes causais, tais como: bactérias (Salmonella e Shigella), vírus (Hepatite A e Rotavírus), Protozoários (Giardia lambia e Entamoeba histolytica), Helmintos (Vermes intestinais e parasitas) e fungos (KEMERICH PDC, 2008; BARBOSA CC, et al., 2012). 
Complementarmente, a água contaminada é capaz de veicular agentes infecciosos ou substâncias capazes de agredir a saúde humana, podendo ser uma potencial via de transmissão de inúmeras doenças, principalmente nos países em desenvolvimento, responsáveis por vários surtos epidêmicos e pelas elevadas taxas de mortalidade infantil, relacionadas à água de consumo humano (BARBOSA CC, et al., 2012; YAMAGUCHI MU, et al., 2013).

O grupo coliforme inclui uma grande variedade em termos de gênero e espécie, principalmente aquelas pertencentes à família enterobacteriae. A maioria das bactérias do grupo coliforme pertence aos gêneros Escherichia sp, Citrobacter sp, klebsiella sp e Enterobacter sp (BARBOSA CC, et al., 2012).

O principal grupo de bactérias termotolerantes é a Escherichia coli, estas geralmente são inofensivas, mas certas linhagens são patogênicas devido a presença de fimbrias e a produção de toxinas, podendo incidir no surgimento de doenças gastrointestinais na população, como gastroenterite (TORTORA GJ, et al., 2017).

Conforme cita Brasil (2007) através da Lei № 11.445 de 2007, complementada e firmada por Brasil (2011) pela Portaria ํo 2914 de 2011 do Ministério da Saúde (MS) que dispõe sobre os procedimentos de controle e reponsabilidades tanto das autoridades sanitárias quanto das operadoras dos sistemas de abastecimento, além de estabelecer a necessidade de vigilância da qualidade da água para consumo humano e padrão de potabilidade da água aceitável.

Segundo Ferreira CS (2017) o Amapá apresenta dificuldade em seguir essas e outras normas relacionadas a qualidade da água para o consumo humano, em virtude das precárias condições de saneamento e do acesso de abastecimento de água tratada.

De acordo com Neri SHA (2004), áreas alagadas em Macapá são denominadas de ressaca, que é uma expressão regional para designar um ecossistema presente na zona costeira do Amapá, caracterizando-se como reservatórios de água. As ocupações nessas áreas são desprovidas de infraestrutura e equipamentos urbanos necessários para boa qualidade de vida.

Este trabalho apresenta um caráter social, visto a importância e preocupação com o uso de água tratada pela população, e para isso, realizou-se a coleta e análise de água em uma área alagada, com o objetivo de verificar a presença de coliformes totais e/ou termotolerantes.

A partir desses aspectos, algumas metodologias de observações, mapeamento da área e análises foram adotadas, como a verificação do destino dos dejetos e a fonte de abastecimento de água.

Nesse contexto, estudar a qualidade da água é fundamental para a certificação de potabilidade para o consumidor, uma água isenta de micro-organismos que possam ser prejudiciais à saúde das pessoas.

Diante disso, esta pesquisa objetivou realizar uma análise microbiológica da água de consumo que é distribuída via tubulação hidráulica para as residências localizadas em um bairro alagado em um município do Amapá.

\section{MÉTODOS}

Trata-se de um estudo transversal, descritivo, quantitativo, realizado através de coletas de amostras de água de 23 residências para avaliar a qualidade da água consumida pela população residente de uma cidade do amapá, que ocupa uma área alagada no período de 2019.

\section{Coleta das amostras}

As coletas foram realizadas em uma passarela localizada em um bairro, situado na periferia da cidade de Macapá. Foram coletadas amostras de água num total de 23 residências localizadas em uma passarela da área alagada do bairro em estudo. De cada casa foram realizadas coletas em duplicata identificadas como $\mathrm{A}$ e B, totalizando assim, 46 amostras analisadas.

A coleta realizada foi acondicionada em frascos estéreis com capacidade para $150 \mathrm{~mL}$, seguindo as normas para coleta de amostras de água contidas do manual prático de análise de água da Fundação Nacional de Saúde - FUNASA, do Ministério da Saúde (BRASIL, 2013). 
Após a coleta, as amostras em cada frasco foram identificadas com um número de registro, correspondente ao ponto de coleta, e foi preenchida uma ficha de identificação da amostra de água. Em seguida, o frasco foi acondicionado em uma caixa de isopor com gelo, lacrada e identificada e enviada imediatamente ao laboratório de Microbiologia da Faculdade Estácio de Macapá, onde as mesmas foram processadas.

Para a análise das coletas foi necessária a utilização do método de Número Mais Provável, que estabelece a quantidade de coliformes por $100 \mathrm{~mL}$. Esse exame microbiológico da água tem como objetivo fornecer informações a respeito da potabilidade da água, que segundo a norma de qualidade da água do Ministério da Saúde, a portaria no 2914/2011 preconiza que águas destinadas para consumo humano devem ter ausência de coliformes totais e termotolerantes (BRASIL, 2011).

Adicionamente, as normas referentes à qualidade microbiológica da água no território brasileiro definem que a água para consume humano deve ser livre de coliformes totais, ou coliformes termotolerantes com ausência em $100 \mathrm{~mL}$. Já para a presença de bactérias heterotróficas, não pode ultrapassar 500 unidades formadoras de colônia por mL (BRASIL, 2011; BARBOSA CC, et al., 2012).

\section{Processamento das amostras}

O método utilizado para análise e quantificação de bactérias do grupo coliformes consiste na técnica de tubos múltiplos, um método probabilístico, em que é possível determinar o Número Mais Provável (NMP) de bactérias do grupo coliformes em $100 \mathrm{~mL}$ de água utilizando tabelas de probabilidade.

Foi realizado o semeio em 15 tubos de ensaios distribuídos de 5 em 5 . Os 5 primeiros tubos em diluição 1:1 (10 mL do meio liquido caldo lactosado de concentração dupla $+10 \mathrm{~mL}$ da amostra), e os 10 tubos restantes, distribuídos em baterias de 5 em 5 , contendo caldo lactosado de concentração simples com diluição 1:10 e 1:100 respectivamente.

Em seguida, os 15 tubos foram incubados a $35 \pm 0,5^{\circ} \mathrm{C}$ durante $24 / 48$ horas. Após o período de incubação, os tubos positivos foram repicados para o caldo verde brilhante (confirmativo para coliformes totais) e para tubos contendo o caldo Escherichia coli (EC) (confirmativo para termotolerantes).

Os tubos com caldo verde brilhantes ficaram incubados a $35 \pm 0,5 \stackrel{\circ}{\circ}$ e os caldos $E C$ incubados a $44,5 \pm$ $0,5 \stackrel{\circ}{ } \mathrm{C}$ por um período de $24 / 48$ horas. Em seguida, realizou-se a leitura dos tubos positivos que apresentavam a presença de gás no tubo de Durhan.

O cálculo do NMP foi realizado por meio da tabela presente no Manual Prático de Análise de Água da Fundação Nacional de Saúde (FUNASA), com limite de confiança de 95\% para as várias combinações de resultados positivos.

A contagem de bactérias heterotróficas foi realizada pelo método "Pour Plate", em que se verte o meio fundido e estabilizado em banho Maria sobre a amostra, o que permite o crescimento bacteriano no interior do ágar e os resultados serão expressos como número de colônias de bactérias/ml ou Unidades Formadoras de Colônias (UFC) /ml.

\section{Considerações Éticas}

De acordo com o que preconizam as resoluções 466/2012 e 510/2016 do Conselho Nacional de Saúde o presente trabalho foi isento de avaliação ou qualquer aquiescência pelo sistema Comitê de Ética em Pesquisa/ Comissão Nacional de Ética em Pesquisa (CEP/CONEP) da Faculdade Estácio de Macapá, de acordo com o protocolo 116/2019 realizado dia 10/10/2019.

\section{RESULTADOS}

A análise microbiológica das amostras coletadas das 23 casas da área alaga em estudo, revelou que 8 destas casas $(34,8 \%)$ tiveram resultados positivos para coliformes totais (Casa 1, Casa 3, Casa 4, Casa 5, Casa 9, Casa 13, Casa 15 e Casa 17) e 6 casas (26.1\%), positivos para coliformes termotolerantes (Casa 1, Casa 4, Casa 5, Casa 13, Casa 15, Casa 17), (Tabela 1). 
Esses resultados evidenciam a presença de coliformes totais e termotolerantes em algumas residências, indicando alto índice de contaminação a saúde humana.

Tabela 1 - Resultado do Número Mais Provável (NMP/100mL) de Coliformes Totais e Coliformes Termotolerantes

\begin{tabular}{|c|c|c|c|c|}
\hline Casas & $\begin{array}{l}\text { Combinações de } \\
\text { Coliformes Totais }\end{array}$ & NMP/100ML & $\begin{array}{l}\text { Combinações de } \\
\text { Termotolerantes }\end{array}$ & NMP/100ML \\
\hline Casa 1 & Positivo & 16 & Positivo & 16 \\
\hline Casa 2 & Negativo & $<2,2$ & Negativo & $<2,2$ \\
\hline Casa 3 & Positivo & 2,2 & Negativo & $<2,2$ \\
\hline Casa 4 & Positivo & 9,2 & Positivo & 2,2 \\
\hline Casa 5 & Positivo & 5,1 & Positivo & 5,1 \\
\hline Casa 6 & Negativo & $<2,2$ & Negativo & $<2,2$ \\
\hline Casa 7 & Negativo & $<2,2$ & Negativo & $<2,2$ \\
\hline Casa 8 & Negativo & $<2,2$ & Negativo & $<2,2$ \\
\hline Casa 9 & Positivo & 2,2 & Negativo & $<2,2$ \\
\hline Casa 10 & Negativo & $<2,2$ & Negativo & $<2,2$ \\
\hline Casa 11 & Negativo & $<2,2$ & Negativo & $<2,2$ \\
\hline Casa 12 & Negativo & $<2,2$ & Negativo & $<2,2$ \\
\hline Casa 13 & Positivo & $>16$ & Positivo & 9,2 \\
\hline Casa 14 & Negativo & $<2,2$ & Negativo & $<2,2$ \\
\hline Casa 15 & Positivo & $>16$ & Positivo & $>16$ \\
\hline Casa 16 & Negativo & $<2,2$ & Negativo & $<2,2$ \\
\hline Casa 17 & Positivo & 2,2 & Positivo & 5,1 \\
\hline Casa 18 & Negativo & $<2,2$ & Negativo & $<2,2$ \\
\hline Casa 19 & Negativo & $<2,2$ & Negativo & $<2,2$ \\
\hline Casa 20 & Negativo & $<2,2$ & Negativo & $<2,2$ \\
\hline Casa 21 & Negativo & $<2,2$ & Negativo & $<2,2$ \\
\hline Casa 22 & Negativo & $<2,2$ & Negativo & $<2,2$ \\
\hline Casa 23 & Negativo & $<2,2$ & Negativo & $<2,2$ \\
\hline
\end{tabular}

Fonte: Porcy C, et al., 2018

Em relação às bactérias heterotróficas, 13 casas $(56,5)$ apresentaram resultados positivos (casa 1 , casa 2 , casa 3 , casa 4 , casa 5 , casa 6 , casa 8 , casa 9 , casa 12 , casa 13 , casa 15 , casa 17 e casa 23 ), sendo que 11 dessas casas $(84,6 \%$ ) apresentaram resultados superiores a $500 \mathrm{UFC} / \mathrm{mL}$ (Tabela 2). A contagem de bactérias heterotróficas é amplamente utilizada como indicador da qualidade da água para consumo humano. 
Tabela 2 - Resultado das casas positivas e negativas para bactérias heterotróficas

\begin{tabular}{lcc}
\hline Casas & Bactérias heterotróficas & Ufc/ml \\
\hline Casa 1 & Positivo & 580 \\
Casa 2 & Positivo & 100 \\
Casa 3 & Positivo & 580 \\
Casa 4 & Positivo & 880 \\
Casa 5 & Positivo & 1180 \\
Casa 6 & Positivo & 1760 \\
Casa 7 & Negativo & -- \\
Casa 8 & Positivo & 4830 \\
Casa 9 & Positivo & 2930 \\
Casa 10 & Negativo & - \\
Casa 11 & Negativo & - \\
Casa 12 & Positivo & - \\
Casa 13 & Positivo & 10.000 \\
Casa 14 & Negativo & 880 \\
Casa 15 & Positivo & - \\
Casa 16 & Negativo & 3.150 \\
Casa 17 & Positivo & -- \\
Casa 18 & Negativo & 580 \\
Casa 19 & Negativo & -- \\
Casa 20 & Negativo & -- \\
Casa 21 & Negativo & -- \\
Casa 22 & Negativo & -- \\
Casa 23 & Positivo & -- \\
\hline
\end{tabular}

Fonte: Porcy C, et al., 2018

\section{DISCUSSÃO}

A água por ser uma necessidade indispensável para a sobrevivência do ser humano, a sua importância para a saúde pública é amplamente reconhecida por parte das autoridades sanitárias e consumidores em geral, particularmente no que se refere a qualidade da água de consumo, visto que sua contaminação pode torná-la um veículo de transmissão de agentes microbiológicos, os quais influenciam diretamente na saúde da população (SCAPIN D, et al., 2012; MEDEIROS AC, et al., 2016).

Adicionalmente, o perfil epidemiológico da má qualidade da água e a presença de doenças de veiculação hídrica tem sido extensamente pesquisada. Considerando-se as normativas da legislação Brasileira, a Portaria 2.914 de 2011, que dispõe sobre os procedimentos de controle e de vigilância da qualidade da água para consumo humano e seu padrão de potabilidade, envolvendo padrões estabelecidos para parâmetros físicos, químicos, microbiológicos, organolépticos, cianobactérias/cianotoxinas e radioatividade.

Adicionalmente, a água avaliada neste estudo não se alinhou com os valores recomendados para consumo humano, aquele que atenda ao padrão de potabilidade estabelecido nesta Portaria e que não ofereça riscos à saúde (BRASIL, 2011).

O exame microbiológico da água tem como objetivo fornecer informações a respeito da potabilidade da água. Para esta ser considerada adequada para o consumo humano, deve apresentar ausência de microrganismos causadores de doenças, principalmente os provenientes da contaminação pelas fezes humanas ou animais de sangue quente, exemplo desse tipo de contaminação é por meio do esgoto sanitário, onde estão presentes microrganismos que podem prejudicar a saúde humana (BRASIL, 2013). 
Esta pesquisa foi realizada em casas localizadas em uma passarela de uma área alagada da cidade de Macapá no Estado do Amapá. Essas áreas são concentrações populacionais em áreas alagadas ou de ressaca, baixadas ou ainda palafitas (diz-se da casa construída acima d'agua, de lago ou de terrenos alagados, sobre estacas de madeira fixas no fundo).

Apesar da iniciativa ter sido do poder público, a área não foi preparada para ser bairro e sofre com sérios problemas de infraestrutura e de risco à saúde pública, apresentando aproximadamente, $80 \%$ de sua área alagada e seus moradores vivem em casas que reproduzem o modelo de moradia de ribeirinhos (pessoas que moram as margens de rios), ou seja, as moradias construídas sobre pontes de madeira.

Por se tratar de uma ocupação irregular (principalmente por suas características ambientais), o bairro enfrenta problemas típicos de ocupações dessa natureza, como a falta de energia elétrica, de água potável, esgoto, coleta de lixo e de outros serviços essenciais e básicos para o indivíduo (VIANA W e MARTINS E, 2014).

O resultado das análises para pesquisa do NMP de coliformes revelou que 8 casas $(34,8 \%)$ tiveram resultados positivos para coliformes totais e 6 casas (26.1\%), positivos para coliformes termotolerantes. Estes resultados acerca da avaliação microbiológica da água também são relatados em alguns estudos realizados em outras regiões do Brasil, com objetivo de avaliar a qualidade microbiológica da água em populações que habitam áreas precárias de saneamento público.

Em um estudo realizado em uma área de baixa renda na cidade Bandeirantes-PR, 47,79\% das amostras apresentaram contaminação por coliformes, com indicativo de água imprópria para consumo humano (OTENIO MH, et al., 2007).

Siqueira LP, et al., (2010) em um estudo realizado em Recife (PE), verificou-se que $62,5 \%$ das amostras de água analisadas, estavam contaminadas por coliformes fecais em desacordos com os padrões microbiológicos adotados no Brasil. De acordo com Michelina AF, et al., (2006), o encontro de coliformes totais em água de consumo humano, serve como indicador das condições higiênico-sanitárias precárias e dos riscos de doenças de veiculação hídrica que atingem, principalmente, crianças e idosos.

É necessário frisar que nessa área em estudo, os moradores informaram que recebem abastecimento de água da estação de tratamento da cidade, no entanto, o despejo dos dejetos humanos é realizado diretamente no lago, por não possuírem rede de esgoto, em que as encanações ficam submersas principalmente em período com maior índice de chuva. Esse fato, aliado a precárias condições das instalações hidráulicas que levam a água até as casas, pode ser a explicação para a contaminação da água de algumas residências por coliformes fecais.

Esses resultados evidenciam a possibilidade de propagação de inúmeros patógenos (bactérias, vírus, protozoários) entre os moradores do bairro ou aqueles que o frequentam. $O$ isolamento de coliformes fecais nestas amostras de água destinadas ao consumo humano, indica a contaminação fecal e consequentemente, a possibilidade da existência de microrganismos patogênicos existentes nas mesmas, podendo ocasionar doenças gastrointestinais na população (SILVA RCA, ARAUJO TM, 2003; KEMERICH PDC, 2008).

Este resultado é importante, visto que bactérias como a Escherichia. coli constituem a causa mais comum de infecção das vias urinárias, sendo responsável por cerca de $90 \%$ de infecções urinárias em mulheres jovens, assim como a doença diarreica. (BROOKS GF, 1998).

Vale ressaltar que mesmo em situações onde a água, chegue à residência em condições de ser consumida, é possível que as condições de manipulação inadequada dos vasilhames, aliada à falta de higiene pessoal, sejam fatores de risco para a transmissão de doenças, quando essa água é consumida sem nenhum tipo de tratamento (SÁ, LLC, et al., 2005).

Em outro estudo realizado na cidade de Ponta Grossa - PR, a presença de coliformes totais e termotolerantes foram identificadas em $89,5 \%$ das amostras de água examinadas, evidenciando o potencial elevado de contaminação e dos riscos de adquirir doenças infecciosas e parasitárias veiculadas pela água contaminada (PILATTI F, HINSCHING MAO, 2008). Em relação às bactérias heterotróficas, a contagem 
dessas bactérias genericamente definidas como microrganismos que requerem carbono orgânico como fonte de nutrientes, fornece informações sobre a qualidade bacteriológica da água de uma forma mais ampla.

Conforme Brasil (2004), a legislação vigente, segundo a Portaria oㅜ 518 de 2004 do Ministério da Saúde, preconiza que a contagem de bactérias heterotróficas em sistemas de distribuição não deve ultrapassar 500 UFC/mL. Desta forma, neste estudo 13 casas $(56,5)$ apresentaram resultados positivos, sendo que 11 dessas casas $(84,6 \%)$ apresentaram resultados superiores a $500 \mathrm{UFC} / \mathrm{mL}$. Importante destacar que algumas dessas amostras foram justamente as amostras que apresentaram a presença de coliformes.

Adicionalmente Freire RC e Lima RA (2012) também identificaram a presença de bactérias heterotróficas, acima do limite permitido, em amostras de água potável em Olinda-PE. As bactérias heterotróficas, usualmente de vida livre, e reconhecidamente patogênicas, tais como Pseudomonas aeruginosa, Flavobacterium, Acinetobacter, Klebsiella, Serratia, Aeromonas apresentam a capacidade de colonizar sistemas de distribuição de água, consistindo em risco à saúde de grupos populacionais vulneráveis.

Para Costa TA, et al (2015) e Nogueira EFR, et al (2018) os possíveis contaminantes da água podem ser inúmeros e se dividem em cinco grupos principais: 1) características sensoriais, que alteram cor, sabor, odor e turbidez da água; 2) de riscos à saúde humana que entram os metais pesados, pesticidas, solventes orgânicos, microrganismos patogênicos, entre outros; 3) Indicadores de depósitos, incrustações e corrosão; 4) Indicadores de poluição e contaminação microbiológica; 5) Dispositivos como as torneiras e/ou os bebedouros, pois estes aparelhos são utilizados para dispensar a água, logo, podem se tornar fontes de contaminação por meio do contato com a água e/ou com o próprio equipamento, seja pelos hábitos de higiene dos usuários, instalação em locais impróprios ou qualidade da água.

Esse contexto, evidencia o impacto do abastecimento de água domiciliar para a saúde de uma população, dependente de diversas variáveis, como as condições ambientais, saneamento pré-existentes e as condições socioeconômicas dos residentes nos domicílios, aliadas aos seus modos de vida. Essa análise para a avaliação de impacto na saúde é relevante e importante em função da qualidade da água distribuída, e da intervenção humana, seja relacionada a higiene, obstrução da rede de distribuição ou outras formas, que possa modificar a qualidade da água fornecida (SÁ, LLC, et al., 2005).

Esses resultados evidenciam ações antrópicas e a vulnerabilidade dessas populações às doenças de veiculação hídrica, sendo necessárias ações de tratamento de dados epidemiológicos, mapeamento de áreas de risco, atendimento médico especializado e soluções viáveis de acordo com cada realidade local para garantir as intervenções que garantam à população o acesso à água em quantidade e qualidade adequadas.

\section{CONCLUSÃO}

Conclui-se que embora as casas sejam servidas por água proveniente da rede de abastecimento de água da estação de tratamento da cidade, as condições hidráulicas em que são servidas compromete sua qualidade ao chegarem no destino, a falta de manutenção nas encanações e o contato com a água da área alagada onde os dejetos humanos são lançados podem ser alguns dos fatores contribuidores para essas contaminações. Portanto, é necessária a atenção sobre a qualidade da água consumida por essas populações que residem em áreas alagadas, visto que estão sujeitas a contaminação devido à falta de saneamento básico e à inexistência de fossas para os destinos dos dejetos. Adicionalmente, a comunidade carece de informações sobre conservação, manejo adequado e qualidade dos recursos hídricos, principalmente quando se trata da água para o consumo.

\section{REFERÊNCIAS}

1. BARBOSA CC, et al. Qualidade microbiológica da água consumida em bebedouros de uma unidade hospitalar no Sul de Minas. Revista Eletrônica Acervo Saúde, 2012; 4(1): 200-211.

2. BARROS FGN, AMIN MM. Água: um bem econômico de valor para o Brasil e o mundo. Revista Brasileira de Gestão e Desenvolvimento Regional, 2008; 4(1): 75-108.

3. BROOKS GF, et al. Microbiologia médica. 20ª edição. Rio de Janeiro: Guanabara Koogan, 1998; 175-84 p. 
4. BRASIL. Ministério da Saúde. Portaria n. 518, de 25 de março de 2004. Dispõe sobre normas e padrões de potabilidade de água para consumo humano. Diário Oficial da União, Brasília, DF, 26 mar. 2004.

5. BRASIL. Ministério da Saúde. Lei № 11.445, de 5 de janeiro de 2007. Estabelece diretrizes nacionais para o saneamento básico. Brasília; 2007.

6. BRASIL. Ministério da Saúde. Portaria 2.914, de 12 de dezembro de 2011. Dispõe sobre os procedimentos de controle e de vigilância da qualidade da água para consumo humano e seu padrão de potabilidade. Diário Oficial da União; 2011.

7. BRASIL. Fundação Nacional de Saúde. Manual prático de análise de água/Fundação Nacional de Saúde. 4ª edição. Brasília: Funasa; 2013. 150p.

8. COSTA TA, et al. Avaliação da qualidade físico-química e microbiológica de águas de bebedouros de escolas do município de Matias Barbosa, Minas Gerais. Revista Eletrônica Acervo Saúde, 2015; 7(1): 736-741.

9. FERREIRA CS. Avaliação bacteriológica, virológica e físico-química da água fornecida a população de Macapá pelo sistema de abastecimento público da Companhia de Água e Esgoto do Amapá. Dissertação (Mestrado em Ciências da Saúde) - Programa de Pós-graduação em Ciências da Saúde. Universidade Federal do Amapá, Macapá, 2017; $122 p$.

10. FREIRE RC, LIMA RA. Bactérias heterotróficas na rede de distribuição de água potável no município de Olinda-PE e sua importância para saúde pública. J Manag Prim Health Care, 2012; 3(2): 91-5.

11. KEMERICH PDC. Água subterrânea e a saúde da comunidade em bairro de Santa Maria - RS. Dissertação (Mestrado em Engenharia Civil) - Programa de Pós-graduação em Engenharia Civil. Universidade Federal de Santa Maria, Rio Grande do Sul, 2008; 118p.

12. MEDEIROS AC, et al. Avaliação da qualidade da água de consumo por comunidades ribeirinhas em áreas de exposição a poluentes urbanos e industriais nos municípios de Abaetetuba e Barcarena no estado do Pará, Brasil. Ciência \& Saúde Coletiva, 2016; 21(3): 695-708.

13. MICHELINA AF, et al. Qualidade microbiológica de águas de sistemas de abastecimento público na região de Araçatuba, SP. Hig Aliment, 2006; 20(147): 90-5.

14. NÉRI SHA. A utilização das ferramentas de geoprocessamento para a identificação de comunidades expostas à hepatite A nas áreas de ressacas dos municípios de Macapá e Santana. Dissertação (Mestrado em engenharia civil) - Programa de Pós-graduação em engenharia civil. Universidade Federal do Rio de Janeiro, Rio de Janeiro, 2004; $189 \mathrm{p}$.

15. NOGUEIRA EFR, et al. Análise comparativa da qualidade da água disponível para consumo nos bebedouros de escolas públicas do município de Santo Inácio do Piauí. Revista Eletrônica Acervo Saúde, 2018. Vol. Sup. 14, S1742S1746.

16. OTENIO MH, et al. Qualidade da água utilizada para consumo humano de comunidades rurais do município de Bandeirantes-PR. Salusvita, 2007; 26(2): 189-95.

17. PILATTI F, HINSCHING MAO. Saneamento Básico Rural na Bacia Hidrográfica do Manancial Alagados. Ponta Grossa, PR: UEPG/SANEPAR; 2008.

18. SÁ, LLC, et al. Qualidade microbiológica da água para consumo humano em duas áreas contempladas com intervenções de saneamento - Belém do Pará, Brasil. Epidemiol. Serv. Saude, 2005; 14(3): 171-180.

19. SALES WB, et al. 2015. Ocorrência de Coliformes Totais e Termotolerantes em pastéis fritos vendidos em bares no centro de Curitiba-PR. Demetra: alimentação, nutrição \& saúde, 2015; 10(1): 77-85

20. SIQUEIRA, LP, et al. Avaliação microbiológica da água de consumo empregada em unidades de alimentação. Ciência \& Saúde Coletiva, 2010; 15(1): 63-6.

21. SILVA RCA, ARAUJO TM. Qualidade da água do manancial subterrâneo em áreas urbanas de Feira de Santana (BA). Ciência \& Saúde Coletiva, 2003; 8(4): 1019-28.

22. SCAPIN D, et al. Qualidade microbiológica da água utilizada para consumo humano na região do extremo oeste de Santa Catarina, Brasil. Rev Inst Adolfo Lutz, 2012; 71(3): 593-6.

23. TORTORA GJ, et al. Microbiologia. 12 $2^{\text {a }}$ edição. Porto Alegre: Artmed; 2017.

24. VIANA W; MARTINS E. Áreas de ressaca em Macapá: a realidade do bairro do Muca. Intercom - Sociedade Brasileira de Estudos Interdisciplinares da Comunicação. In: XXI Prêmio Expocom 2014 - Exposição da Pesquisa Experimental em Comunicação. 2014.

25. YAMAGUCHI MU, et al. Qualidade microbiológica da água para consumo humano em instituição de ensino de Maringá-PR. O Mundo da Saúde, 2013; 37(3): 312-320. 